Results: Among the 541 patients screened, hypertension was present in $28.1 \%$ patients, dyslipidemia in $19.2 \%$, chronic respiratory tract diseases in $12.8 \%$ and diabetes in $9.6 \%$. Screening led to the following recommendations: blood pressure monitoring (22.6\% patients), dietary advice $(56.8 \%)$, cardiologist referral $(35.5 \%)$, intensification of physical activity $(27.0 \%)$, cancer screening $(50.5 \%)$, vaccinations $(60.6 \%)$ and vitamino-calcium supplementation $(30.3 \%)$. On the 237 patients called back, $72.3 \%$ underwent blood pressure monitoring, $58.6 \%$ followed dietary advice, $64.4 \%$ took vitamino-calcium supplementation, $55.2 \%$ had vaccinations done, $52.1 \%$ saw a cardiologist, $42.7 \%$ increased physical activity and $31.4 \%$ performed cancer screening. No specific gender, age, pathology, or psychological factors were associated with adherence to recommendations.

Conclusions: This study underlines the relevance of a systematic screening of multimorbidities in chronic inflammatory rheumatic diseases, and the good patient's adherence rate to the recommendations.

Disclosure of Interest: None declared

DOI: 10.1136/annrheumdis-2018-eular.3756

\section{AB1258 EARLY ARTHRITIS SERVICE IS COST EFFECTIVE, IMPROVES OUTCOMES AND REDUCES BIOLOGIC USE}

G.A. Niazi, M.K. Nisar. Rheumatology, Luton and Dunstable University Hospital, Luton, UK

Background: There is good evidence that dedicated early arthritis clinics (EACs) improve referral lag time and reduce delay in establishing disease-modifying therapy. However it remains arguable whether such clinics improve relevant disease outcomes. Nationally, only $57 \%$ of units have dedicated EACs.

Objectives: We established Early Arthritis Service (EAS), centred on NICE RA quality standards, to reduce the time to diagnosis and the start of definitive therapy with an aim to accomplish good outcomes by the introduction of dedicated Early Arthritis Clinics (EACs).

Methods: The department set up an early arthritis service with introduction of six clinics (EACs) every week. An agreed treatment protocol incorporating ultrasound was developed to ensure standardised approach to early initiation of treatment, drug education and timely review. This is a retrospective study of all patients presenting to the service in the first year.

Results: Our catchment area covers a population of 350000 with $40 \%$ ethnic minorities. Of 1884 patients referred, 482 (25.5\%) were triaged into EACs based on set criteria. All were reviewed within 3 weeks. 247 (51\%) were confirmed to have early arthritis. Mean age was 52.4 years (17-86y). 157 (63.5\%) were women. 177 $(71.6 \%)$ were White, $58(23.5 \%)$ of Asian and twelve of other background. 159 $(64.3 \%)$ had RA, 57 (23\%) with PsA and 31 had other inflammatory arthritides. 25 $(10 \%)$ had erosions at presentation. There was median 26 weeks delay (0.41043 weeks) from symptom onset to GP presentation. Median time for GP referral to the department was 4.0 days (0-84 days). Mean DAS28 at first visit was 4.65 $(0.6-8.0, \mathrm{n}=166)$

$95 \%$ commenced their DMARDs within 3 week of initial review. Other $5 \%$ who missed the target was owing to patient factors. Treating to target achieved DAS28 remission for $84(53.5 \%)$ and low disease activity for a further $44(34 \%)$. Median time to achieve remission or LDA was 20 weeks ( $0-52$ weeks, $n=128)$. Similarly, $40 / 57(70 \%)$ of PsA patients achieved good PsARC response in median 24 weeks. Of 247 , only 21 ( $8.5 \%$ ) patients required escalation to biologic therapy. Conclusions: Dedicated EACs help achieve good clinical outcomes in majority of patients. Nearly $87 \%$ of our cohort attained remission or low disease activity in less than six months. This was despite a significant delay in patients presenting to their GPs and moderately-high disease activity. $100 \%$ of our patients were treated to target facilitated by protocol driven escalation of therapy in these clinics. This is in contrast to the national audit findings whereby only $68 \%$ of patients were treated with disease modifying drugs within 6 weeks of referral and $89 \%$ had treatment to target. Patient experience also improved ( $94 \%$ would now recommend the service compared to $76 \%$ prior to the initiative).

The project was a financial success with total savings for the year, accounting for most generous cost estimates, were $£ 136$ 973. In addition, there was a $42 \%$ reduction in biologic use in this group compared to 2015 . These savings are on top of wider economic and societal benefits achieved by inducing low disease activity or remission.

Disclosure of Interest: None declared

DOI: 10.1136/annrheumdis-2018-eular.1329

\section{AB1259 IS DOSE BANDING OF INFLIXIMAB COST EFFECTIVE - RESULTS FROM REAL WORLD IMPLEMENTATION}

\section{M.K. Nisar. Rheumatology, Luton and Dunstable University Hospital, Luton, UK}

Background: Infliximab dose is based on the patient's body weight (3-5 mg/kg) and requires the use of multiple $100 \mathrm{mg}$ vials to reconstitute the individualised dose. As the product is expensive, there is a significant cost associated with unused and wasted infliximab in any part-used vials. "Dose banding" is one solu tion so that patients receive a pre-prepared dose produced in advance in batches where wastage from part vials is minimised. There is some encouraging data that reconstituted infliximab is stable for long enough to allow batch production of preprepared doses. The theoretical risk of course is over or under treatment while respectively rounding up or down the administered dose.

Objectives: We undertook a retrospective analysis of our experience of dose banding in rheumatology unit.

Methods: All patients prescribed infliximab for rheumatic indication at our centre were included in the analysis. Case notes were retrospectively reviewed to look a dose variance following implementation of this initiative, resultant disease contro and the consequent cost savings.

Results: 10 patients prescribed infliximab biosimilar and two bio-originator were identified for the analysis. Median age was 55.5 years (range $25-80$ years). Nine had the drug for RA, two for AS and one for myositis.

Three had no change in dose as a result of implementing dose banding program. Three had dose increased by $3 \%-5 \%$. Remaining six had dose reduced by range of $4 \%-6 \%$. Their disease scores before and after dose banding remained largely unchanged (table 1). This equated to $£ 1,184.58$ annual savings in addition to the economic benefit of successfully switching the ten patients to biosimilar. No patient suffered loss of efficacy or adverse events in any of the three groups.

Conclusions: Our data confirms the utility of dose banding program for infliximab in rheumatology practice with no concerns about efficacy or safety of the initiative. There are potential opportunities to achieve considerable reductions in medicines discarded and improving finances by adopting dose banding for infliximab. It also helped curb over $£ 10000$ expense to our Trust in infliximab waste cost alone. There are some important caveats to consider as well. True savings will depend on list price of each product and varies with originator versus biosimilar. The variance increases as the width of the dose bands increases i.e. the variance is greater at lower body weights. Consequently, depending on patient population both clinical and cost considerations could alter. Finally, assurance of the product

Abstract AB1259 - Table 1

\begin{tabular}{|c|c|c|c|c|c|c|c|c|c|c|}
\hline Age & Sex & Ethnicity & Indication & $\begin{array}{l}\text { Prior dose } \\
\quad(\mathrm{mg})\end{array}$ & $\begin{array}{l}\text { Pre banding } \\
\text { Disease } \\
\text { score }\end{array}$ & $\begin{array}{c}\text { New dose } \\
(\mathrm{mg})\end{array}$ & $\begin{array}{l}\text { Post banding } \\
\text { Disease } \\
\text { score }\end{array}$ & Variance & $\begin{array}{l}\text { Dose } \\
\text { vials }\end{array}$ & $\begin{array}{c}\text { Saving } \\
\text { (12 month) }\end{array}$ \\
\hline 48 & $M$ & Mixed & AS & 400 & 3.2 & 400 & 3.9 & $0 \%$ & 4 & $£ 0.00$ \\
\hline 58 & $\mathrm{~F}$ & White & RA & 210 & 2.3 & 200 & 2.8 & $-5 \%$ & 2 & $£ 87.00$ \\
\hline 54 & $\mathrm{~F}$ & White & RA & 300 & 3.6 & 300 & 1.7 & $0 \%$ & 3 & $£ 0.00$ \\
\hline 44 & $\mathrm{~F}$ & White & RA & 210 & 2.2 & 200 & 1.8 & $-5 \%$ & 3 & $£ 87.00$ \\
\hline 78 & $\mathrm{~F}$ & Asian & RA & 170 & 4.1 & 175 & 3.3 & $3 \%$ & 2 & $-£ 43.50$ \\
\hline 56 & $\mathrm{~F}$ & White & RA & 300 & 2.5 & 300 & 2.1 & $0 \%$ & 2 & $£ 0.00$ \\
\hline 73 & $\mathrm{~F}$ & White & RA & 210 & 3.9 & 200 & 3.9 & $-5 \%$ & 2 & $£ 87.00$ \\
\hline 80 & $\mathrm{~F}$ & White & RA & 190 & 3.8 & 200 & 3.8 & $5 \%$ & 3 & $-£ 87.00$ \\
\hline 49 & $\mathrm{~F}$ & White & RA & 210 & 2.3 & 200 & 3.4 & $-5 \%$ & 3 & $£ 87.00$ \\
\hline 55 & $M$ & White & AS & 320 & 0.2 & 300 & 0.4 & $-6 \%$ & 2 & $£ 174.00$ \\
\hline \multicolumn{11}{|c|}{ Bio-originator } \\
\hline \multicolumn{11}{|c|}{ Patients } \\
\hline 25 & $\mathrm{~F}$ & White & RA & 120 & 4.1 & 125 & 4.1 & $4 \%$ & 0 & $£ 0.00$ \\
\hline 49 & $\mathrm{~F}$ & White & Myositis & 470 & $\begin{array}{c}\text { Well } \\
\text { controlled }\end{array}$ & 450 & $\begin{array}{c}\text { Well } \\
\text { controlled }\end{array}$ & $-4 \%$ & 0 & $£ 793.08$ \\
\hline
\end{tabular}

